1 Secretaria Municipal de Saúde (SMS), Unidade de Saúde da Família dos Sinos - Recife (PE), Brasil. adrianalopes79@hotmail. com

2 Universidade Federal do Rio Grande do Norte (UFRN), Rede Nordeste de Formação em Saúde da Família (Renasf) - Natal (RN), Brasil.

rosanaalvesrn@gmail.com

3 Secretaria Municipal de Saúde (SMS), Estratégia Saúde da Família de Monte Líbano e Programa de Educação pelo Trabalho para a Saúde (PET-Saúde) - Natal (RN), Brasil. Universidade Federal do Rio Grande do Norte (UFRN), Residência

Multiprofissional de Saúde

- Natal (RN), Brasil.

ricardohvm@gmail.com

4 Universidade Federal do Rio Grande do Norte (UFRN) - Natal (RN),

Brasil.

raiane_mell@hotmail.com

\section{O acolhimento na Atenção Básica em saúde: relações de reciprocidade entre trabalhadores e usuários}

\author{
The hospitality in Primary Health Care: relations of reciprocity \\ between workers and users
}

Adriana Santos Lopes', Rosana Lúcia Alves de Vilar², Ricardo Henrique Vieira de Melo², Raiane Caroline da Silva França $\mathbf{4}$

RESUMO Esta pesquisa aborda a prática do acolhimento analisando as relações de reciprocidade entre trabalhadores e usuários, na Estratégia Saúde da Família. Trata-se de uma investigação descritiva, explicativa e qualitativa, com coleta de dados através de entrevistas semiestruturadas e análise pela técnica do discurso do sujeito coletivo. Os resultados evidenciaram que a normatização repercute nas relações de reciprocidade. $\mathrm{O}$ acolhimento favoreceu a troca de dádivas. Entretanto, aspectos referentes à estrutura física deficiente, à demanda excessiva, à precariedade da rede de referência, à visão médico-centrada, à vulnerabilidade da população, dificultaram as relações mútuas entre os sujeitos.

PALAVRAS-CHAVE Acolhimento; Estratégia Saúde da Família; Humanização da assistência.

\begin{abstract}
This research addresses the practice of hospitality, analyzing the relationships of reciprocity between workers and users in the Family Health Strategy. This is a descriptive, explanatory and qualitative research, with data collection through semi-structured interviews and analysis by the collective subject's discourse technique. The results showed that the regulation has repercussion on the relations of reciprocity. The hospitality has favored the exchange of gifts. However, aspects related to the poor physical infrastructure, to the excessive demand, to the precariousness of the reference network, to the physician-centered vision and to the vulnerability of the population, have hindered the mutual relations between subjects.
\end{abstract}

KEYWORDS Hospitality; Family Health Strategy; Humanization of assistance. 


\section{Introdução}

O Sistema Único de Saúde (SUS) preconiza, em sua política de saúde, um conjunto de ações que possibilitem a execução dos princípios da universalidade do acesso; a integralidade e a equidade da atenção à saúde; descentralização da gestão; regionalização e hierarquização; e participação popular por intermédio do controle social. O acesso da comunidade e a forma de recepcioná-la constituem-se como pontos importantes a serem considerados para viabilizar a execução desses princípios e, portanto, devem ser revistos e aperfeiçoados no contexto da prática e da organização dos serviços de saúde. A desqualificação do cuidado ao usuário reflete a falta de comunicação entre profissionais e população, o que impossibilita que as reais necessidades deste último segmento sejam reveladas, dificultando a diversificação das práticas de atenção à saúde e fazendo com que os serviços se organizem a partir de uma demanda limitada de procedimentos (CAMPOS, 2006; LOPES, 2014).

A Política Nacional de Humanização (PNH), idealizada pelo Ministério da Saúde (MS), surgiu como uma proposta para requalificar essa atenção, de modo a manter uma associação entre as formas de produzir saúde e as formas de administrar os processos de trabalho, entre atenção e gestão, entre clínica e política, entre produção de saúde e produção de subjetividade. Esta política objetiva possibilitar inovações nas ações gerenciais e nas ações de produção de saúde, de modo a propor novas formas de organização dos serviços de saúde.

As abordagens teóricas e organizativas da $\mathrm{PNH}$ demonstram que essa política surgiu para impulsionar a efetivação de um SUS inclusivo, democrático, resolutivo e acolhedor. Apresentam conceitos amplificados sobre a humanização, de forma a agregar valores diversos: 'organizativo' porque se refere às formas de organizar os serviços de saúde; 'gerencial' por abordar o modo de gestão e a coordenação do trabalho desenvolvido; e 'relacional' por referir-se ao relacionamento consolidado entre os indivíduos que participam do processo de trabalho em saúde, que são os gestores, os trabalhadores e os usuários (MENDES, 2010; VILAR, 2014).

Para pôr em prática esses conceitos, a $\mathrm{PNH}$ fundamenta-se em algumas diretrizes específicas para a Atenção Básica, que enfatiza: a elaboração de projetos individuais; o incentivo às práticas de promoção da saúde; o acolhimento e a inclusão do usuário no sistema, na perspectiva da garantia do acesso e da resolubilidade, além do trabalho em equipe, para gerar uma maior corresponsabilidade na atenção (BRASIL, 2004).

Em documento oficial desta política, o acolhimento é definido por:

Processo constitutivo das práticas de produção e promoção de saúde, que implica responsabilização do trabalhador/equipe pelo usuário, desde a sua chegada até sua saída, ouvindo sua queixa, considerando suas preocupações e angústias, fazendo uso de uma escuta qualificada, que possibilite analisar a demanda e, colocando os limites necessários, garantir atenção integral, resolutiva e responsável por meio do acionamento/articulação das redes internas dos serviços (visando à horizontalidade do cuidado) e redes externas, com outros serviços de saúde, para continuidade da assistência quando necessário. (BRASIL, 2004, P. 14).

O acolhimento possui três esferas constitutivas: postura, atitude e tecnologia do cuidado; mecanismo de ampliação e facilitação do acesso; e dispositivo de (re)organização do processo de trabalho em equipe (BRASIL, 2010; BRASIL, 2011). Nesta percepção, o acolhimento adquire o discurso de inclusão social em defesa do SUS, subsidiando a geração de reflexões e mudanças na organização dos serviços e na postura dos profissionais, na ideia do acesso universal, na retomada da equipe multiprofissional e na qualificação 
do vínculo entre usuários e profissionais de saúde (MITRE; ANDRADE; COTTA, 2012).

Dessa forma, pode-se afirmar que o acolhimento é uma ação que deve existir em todas as relações de cuidado, no vínculo entre trabalhadores de saúde e usuários, na prática de receber e escutar as pessoas, e deve ser estabelecido como uma ferramenta que: possibilite a humanização do cuidado; amplie o acesso da população aos serviços de saúde; assegure a resolução dos problemas; coordene os serviços; e vincule a efetivação de relações entre profissionais e usuários. Neste sentido, pode-se afirmar que a prática do acolhimento está presente em todas as relações de cuidado e pode se configurar de diferentes formas dependendo de quem participa dos processos e de como e em que condições este processo se dá. À vista disso, em vez de indagar se, em algum serviço, existe ou não o uso da ferramenta acolhimento, talvez seja mais pertinente avaliar como ele se concretiza ou é empregado. O acolhimento é transmitido menos no discurso sobre ele do que nas práticas propriamente ditas (BRASIL, 2011; LOPES, 2014).

No momento em que se fala da equipe multiprofissional, existe a inter-relação dos diferentes saberes, almejando sobrepor a desintegração no objetivo de construir novas respostas às demandas propostas. Ademais, esta proporção abrange tanto as vinculações entre os profissionais e usuários como também as relações entre os profissionais que compõem a equipe multidisciplinar, como vínculos democráticos, que encorajam a participação, a autonomia e a decisão coletiva (SCHMIDT; FIGUEIREDO, 2009).

Esses conceitos estão relacionados ao reconhecimento da saúde como direito de cidadania, e à imprescindibilidade da geração de novos territórios existenciais e organizacionais, que valorizem o indivíduo e sua coletividade, e produzam possibilidades de interações, trocas e criações, embasadas pelas teorias da dádiva e da reciprocidade, representadas por valores como interação social, solidariedade, respeito e responsabilização (VILAR, 2014).

Nos seus estudos Mauss (2003) concebe a teoria da dádiva como universal no campo das relações sociais, traduzindo-se a partir da tríplice obrigação coletiva de doação, recebimento e retribuição, perfazendo uma lógica organizativa do social. E, por assim ser, incorpora um sentido dialético, integrando obrigação e liberdade, interesse e espontaneidade, demonstrando que as regras sociais são incertas e não podem ser condicionadas apenas às dimensões do mercado ou do Estado. Neste sentido, não considera a realidade social limitada a recortes empiristas ou materialistas, estando também presentes as dimensões afetivas e simbólicas.

Para Sabourin (2008), a reciprocidade é um princípio base para as obrigações sociais, voluntárias ou não, como também para relações íntimas ou distantes. Valores ou dádivas como justiça, equidade, obrigação, respeito, gratidão, responsabilidade perante o outro e obrigação de obediência às leis estão presentes nas relações de reciprocidade e no ato de cuidar.

A natureza das relações de reciprocidade entre usuários que têm necessidades de saúde e trabalhadores que reconhecem essas necessidades é a da produção de um processo onde há acolhimento do outro, compreensão e significação de suas singularidades e oferta dos saberes em saúde que venham permitir ao profissional intervenções continuadas de vínculo, produção de autonomia e responsabilização pelo resultado destas intervenções (CAVALCANTE FILHO; VASCONCELOS; CECCIM ET AL., 2009).

Torna-se evidente que as relações no acolhimento são permeadas pelas teorias da dádiva e da reciprocidade, uma vez que, quem se relaciona/acolhe, sempre tem algo a oferecer, mas também espera do outro algo em troca, e este processo também é recíproco por quem é acolhido. No seu sentido legítimo, o acolhimento pretende humanizar as relações entre trabalhadores e serviços de saúde com seus usuários, 
através de escuta qualificada, formação de vínculo e respeito, sempre com uma resposta positiva e com a responsabilização pela solução do seu problema, mas cabe lembrar que este processo relacional também recebe inúmeras influências. Nas sociedades capitalistas, a relação entre as pessoas tende a apresentar uma motivação mais utilitarista, resumida a interesses materiais. Entretanto, a ocorrência de trocas de sentimentos e atitudes, ditas simbólicas, podem se manifestar de forma positiva ou negativa (LOPES, 2004).

A pesquisa analisou a prática do acolhimento e suas contribuições nas relações de reciprocidade entre trabalhadores e usuários, identificando fatores que favorecem ou dificultam as relações de reciprocidade entre eles.

\section{Metodologia}

A investigação foi realizada em Unidades de Saúde da Família (USF) de um município brasileiro de grande porte. A seleção ocorreu por meio de sorteio entre as unidades deste distrito, que implementaram o acolhimento nos processos de trabalho de suas equipes. $\mathrm{O}$ público pesquisado foram os usuários e trabalhadores de saúde que participavam do acolhimento nas referidas unidades, distribuídas nas três microrregiões de saúde.

Nas USF sorteadas, a pesquisa foi realizada com os representantes dos trabalhadores, na proporção de até 3 do nível superior, 1 do nível técnico (de enfermagem ou de higiene dental) e 4 Agentes Comunitários de Saúde (ACS), além de 4 representantes dos usuários que tiveram a oportunidade de vivenciar a prática do acolhimento nas determinadas unidades, finalizando o total de 12 pesquisados por unidade; dentre eles, 8 profissionais e 4 usuários. Ressalte-se a exceção de duas unidades, posto que, em uma delas, um profissional negou-se a responder e, na outra, o profissional estava, no momento da entrevista, em licença médica. Sendo assim, a amostra totalizou 30 profissionais e 16 usuários.

A amostra se deu pela forma aleatória simples, com escolha das unidades participantes a partir da condição do acolhimento implantado, proposto pela prefeitura do município em questão e, por conseguinte, foi efetuado um sorteio aleatório. Este tipo de amostra se fundamenta nas leis da probabilidade e garante a austeridade científica pelo fato de ser selecionada ao acaso, eliminando-se o conhecimento antecedente de que o pesquisador possa dispor.

Buscando uma melhor adequação dos sujeitos da amostra para o estudo, alguns fatores de inclusão e exclusão foram definidos, tais como: Profissionais das USF sorteadas nos respectivos territórios, na quantidade demonstrada anteriormente, que estivessem trabalhando na unidade há pelo menos um ano e se dispusessem a participar do estudo; e usuários que tivessem recebido atendimento por parte da equipe de acolhimento no quantitativo já referido, que residissem na área de abrangência, que frequentassem a unidade há pelo menos um ano e se dispusessem a participar do estudo após convite do pesquisador. Os critérios de exclusão se reportaram a todos os profissionais e usuários que não estavam inseridos nos padrões estabelecidos para inclusão na pesquisa.

A coleta de dados foi realizada através de uma entrevista semiestruturada direcionada aos profissionais e aos usuários estabelecidos, por meio de formulários de pergunta previamente construídos. Esses formulários foram distintos, um para o profissional e outro para o usuário.

As falas dos diferentes declarantes foram registradas através de gravação digital de voz, e depois, transcritas de forma manual e literal, porém com as devidas correções gramaticais e dos vícios de linguagem, preservando a autenticidade do que foi expresso pelos sujeitos. 
Para avaliar os fatores facilitadores e dificultadores nas relações de reciprocidade, foi utilizada a abordagem metodológica do Discurso do Sujeito Coletivo (DSC).

Nesta técnica o sujeito coletivo se expressa através de um discurso emitido do que se poderia chamar de primeira pessoa (coletiva) do singular. Trata-se de um eu sintático que, ao mesmo tempo em que sinaliza a presença de um sujeito individual do discurso, expressa uma referência coletiva, na medida em que esse eu fala pela ou em nome de uma coletividade, isto é, a expressão de um ou mais sujeitos coletivos, viabilizando um pensamento social. (LEFÈVRE; LEFÈVRE, 2003, P. 16).

Em seguida, foram identificadas as 'Ideias Centrais' (IC) e as 'Ancoragens' (AC) que estão presentes no DSC.

As IC são pedaços, ou trechos, ou segmentos, contínuos ou descontínuos, do discurso, são abstratas, conceituais, sintéticas, frias e poucas. As IC são o que o entrevistado quis dizer (ou o quê, sobre o quê). (LEFÈVRE; LEFÈVRE, 2012, P. 77).

Já as AC não se referem aos sentidos, mas sim às ideias, aos valores, às crenças, presentes no conteúdo verbal das respostas individuais ou das agrupadas, sob a forma de afirmações genéricas destinadas a enquadrar situações particulares. Os DSC foram apurados com a utilização do programa QualiQuantiSoft, que possibilita a união das IC e/ou AC de sentido similar ou complementar e, desta forma, possibilita a geração dos discursos coletivos (LEFÈVRE; LEFÈVRE, 2005).

A pesquisa foi realizada cumprindo os preceitos éticos, segundo a Resolução nº 466/12 (BRASIL, 2012), do Conselho Nacional de Saúde (CNS), que define as diretrizes e normas regulamentadoras que regem a pesquisa envolvendo seres humanos, e foi aprovada por Comitê de Ética (CAAE no 14670113.8.0000.5292), através de Parecer Consubstanciado ( ${ }^{\circ}$ 312.347), em 21/06/2013. Foi empregado um código ao discurso dos participantes, para reduzir ao mínimo o risco de identificação dos mesmos.

\section{Resultados e discussão}

Para a avaliação dos resultados foram selecionadas algumas IC e seus determinados discursos coletivos, tanto de profissionais como de usuários. As IC e as AC estão destacadas em aspas simples. Os discursos foram representados, por meio de trechos de falas, e no decorrer do texto, foi realizada uma análise com embasamento na literatura científica.

A prática do acolhimento, como ferramenta proposta pela $\mathrm{PNH}$, já referida em discussão antecedente, foi utilizada para ampliar o acesso dos usuários ao serviço de saúde, organizar o processo de trabalho e trazer qualificação à relação entre profissionais e usuários, através da formação de vínculos, promoção da autonomia e garantia da responsabilização. Dessa forma, percebemos que o acolhimento é entendido como um recurso de mediação de grande relevância na Atenção Básica, no momento em que cria uma relação de confiança com a população, e os profissionais conseguem desenvolver uma relação de dádiva com os usuários (BEZERRA; CARVALHO, 2011).

Após a implementação do acolhimento nas USF pesquisadas, usuários e profissionais relataram no DSC uma 'melhoria na relação usuário-profissional'. Elementos da reciprocidade, como afetividade, atitude acolhedora, respeito e cuidado com o outro apareceram como incentivadores dessa relação.

Eu acho que assim está mais ameno, melhorou, até por conta do atendimento da doutora, com relação ao paciente. Os médicos estão atendendo melhor também. Perguntam, com tranquilidade, com delicadeza. Isto é positivo. (USU07; USU14; USU16).

Pelo acolhimento inicial, eles ficam até satisfeitos, porque aqui eles são acolhidos, são atendidos nas necessidades básicas que a unidade oferece. Chegam aqui e dizem que são tratados bem, que a gente sempre está de cara bonita. Eles estão gostando do jeito que estão sendo acolhidos e 
elogiam: 'poxa, vocês atenderam tão bem!'. O fato de a gente sentar, escutar faz com que eles se sintam bem acolhidos. A gente está até escutando elogios agora. (PROF10; PROF08; PROF29).

Valores tais como cuidado, atitude acolhedora, afetividade e respeito também foram encontrados nos discursos dos usuários que enfatizaram como IC 'a melhoria no acesso ao serviço e ao profissional potencializou a construção de vínculos entre eles'.

A relação melhorou, com certeza. Eu, particularmente, acho que sim, porque, antigamente, para marcar, para falar com a médica, para marcar consulta, o paciente esperava muito, tinha que chegar muito cedo, era mais difícil. O acesso agora está bem melhor, é bem mais rápido. Hoje mesmo já vou ser atendida. Eu acredito que está melhor, por esse motivo, posso chegar com meu problema e ser atendida no mesmo dia, na mesma hora. (USU02; USU01; USU03; USU15; USU04).

Os profissionais no DSC afirmaram, ainda, que 'a melhoria do acesso ao serviço facilitou as relações com os usuários'.

Eu acho que, depois do acolhimento, você consegue ver onde tem mais riscos, mais vulnerabilidade. Porque, às vezes, 'haviam' pacientes que não conseguiam vir marcar consulta, quando era marcado na fila, porque tinha que pegar ficha de madrugada. Então, assim, hoje você está conseguindo atingir um número maior de pessoas, que antigamente não vinham [...]. Agora, temos aquela satisfação de saber que a pessoa virá e não encontrará 'só cinco fichas', como eles dizem. E eles vão poder ser marcados ou vistos no mesmo dia. Às vezes, não se resolve tudo que o usuário precisa, mas pelo menos, ele tem a satisfação de chegar, ser escutado, pel'a gente, pela médica, pelas enfermeiras. (PROFO3; PROF06; PROF07; PROF11; PROF30).

Alguns profissionais evidenciaram que 'as relações de vínculo melhoraram porque também melhorou o acesso ao profissional'.
Eu acredito que existiram várias mudanças de forma positiva. A relação da comunidade com o profissional melhorou, porque a gente consegue passar ideias. A gente também consegue vir com novas sugestões. Aproximou, sabe? Com relação ao que se tinha antes e o de hoje, tem um estreitamento das relações. E os usuários estão mais próximos e participando mais aqui dentro da unidade. Estão frequentando mais, já estão compreendendo, mais ou menos, o que é o acolhimento. Aos pouquinhos, eles estão entendendo que o fluxo mudou. (PROF01; PROF02; PROF13; PROF21; PROF24; PROF26; PROF29).

Porém, o entendimento de que a afetividade é uma motivação da ação social que tem sinais diversos, e depende do modo como os sujeitos envolvidos agem reflexivamente sobre sua memória e sua prática, pode ter um sinal concordante, favorecendo as trocas, ou discordante, inibindo as trocas (PINHEIRO; MARTINS, 2011).

Foi relatado, também, na IC de discursos dos profissionais, que 'a construção de vínculos, às vezes, se configura de forma tão intensa, que tem dificuldades de negar ações ao usuário'.

Assim, eu estou aqui há mais de nove anos na unidade. Então, a gente é mais do que posto, a gente é mais do que saúde; é tudo para a comunidade. É um pouquinho de tudo: é um pouquinho de psicóloga, de assistente social. Então, assim, a relação só fez ficar mais cúmplice. A gente é como se fosse família da comunidade, sabe? A gente sente muita dificuldade em dizer não, porque já criou raiz, já criou um laço, e a gente pensa muito antes de dizer um não. (PROF25; PROF10; PROF08).

Nessa situação, a medida da afetividade deve ser controlada de forma a não prejudicar a relação profissional-usuário, pelo fato de o usuário querer se valer disso para obter preferência, construindo uma reciprocidade assimétrica. No mesmo sentido da obtenção de vantagem, juntamente com o desafeto, a descrença e a não confiança, estas formas de 
reciprocidade, tidas como negativas, podem aparecer nas relações entre profissionais e usuários que 'desejam que seus problemas sejam resolvidos de forma ágil e da maneira que os mesmos esperam'.

A gente tem que ter funcionários eficientes, que venham trabalhar na hora certa, que atendam a gente com habilidade, com paciência de escutar o problema e de tentar resolver. Acho que é necessário ter mais consideração com as pessoas, pois o tratamento fica mais agradável. Porque se você é bem atendido, as pessoas saem bastante satisfeitas. Não é? (USU08; USU12; USU15).

Satisfeitos, satisfeitos acho que nunca estão. Até porque não conseguimos resolver os problemas de todos: até porque alguns querem ser atendidos no mesmo dia, querem que seja resolvido na hora, independente da queixa. Quando é caso de intercorrência, tudo bem. Mas as pessoas querem marcar de qualquer jeito, naquele dia, naquele horário, ser atendidas. Mas, nem sempre, a necessidade daquele paciente é de uma urgência [...]. Eles acham que a resposta positiva é uma resposta imediata. (PROF01; PROF03; PROF13; PROF18; PROF26; PROF30).

A resolução positiva proposta pelo acolhimento pode ser compreendida de forma confusa pelo usuário, e o mesmo não entender a conduta do profissional, dificultando a troca de dádivas entre eles. Alguns usuários relataram que eles só 'consideram que tiveram a resposta positiva porque obtiveram algum benefício pessoal', ou seja, foi feito o que os mesmos esperavam.

Na realidade, assim, o acolhimento tem esse papel, de selecionar e avaliar a demanda, para que possa ser resolvido. Então, nesse momento, eu fui contemplado: ela me deu a medicação, me deu o resultado do meu exame [...] tudo perfeito. (USU12; USU06; USU07; USU16; USU01).

Um fato relatado por alguns profissionais foi o de que 'a pouca compreensão da comunidade em relação ao acolhimento dificulta as relações de trocas entre usuários e profissionais'.

Eu acho até que os profissionais estão abertos para essa nova estratégia. O problema é a comunidade, que é o grande entrave da política. Eles estão muito habituados com o antigo modo assistencial de saúde. Eu acho que, a partir do momento em que eles entendem como é o acoIhimento, eu creio que eles possam colaborar, no sentido de ficarem menos ansiosos para serem atendidos imediatamente, por saberem que o problema deles pode ser resolvido durante a semana. Então, eles podem vir com mais tranquilidade. (PROF01; PROF05; PROF10; PROF16; PROF26; PROF30).

Este fato pode ser entendido pela precariedade da informação, tanto dos usuários quanto dos profissionais, como também pela falta de um serviço estruturado, considerando a estratégia do acolhimento (LOPES, 2014).

Outra IC identificada foi 'a demanda excessiva como dificultadora das trocas recíprocas'.

Olhe, eu acho que eles não estão muito satisfeitos, não. A gente procura dar o máximo que a gente pode, mas eu acho que eles não estão satisfeitos porque a grande procura no acolhimento é a marcação de consulta. E a consulta, por ser uma demanda muito grande de pacientes, não está sendo muito rápida, e tem gente que fica sem atendimento. Não dá para atender todo mundo. Além disso, agente não consegue fazer a escuta qualificada, como pede o acolhimento, por conta da demanda que a gente tem. Então, a gente não consegue dar aquela devida atenção ao paciente. (PROFO4; PROF05; PROF06; PROF07; PROF16; PROF20; PROF22; PROF28).

Critérios como 'comunicação entre os membros da equipe, agilidade no atendimento e problemas com a demanda melhorariam as trocas recíprocas' foram relatados nas IC como passíveis de serem resolvidas 
pela própria equipe. "Acho que precisamos melhorar a comunicação entre os membros da equipe. Já melhorou bastante, mas ainda é falha" (PROF01; PROF18).

Fatores como 'estrutura física, grande demanda de atividades e resolutividade da rede de referência potencializariam as trocas recíprocas'.

Acredito que possa melhorar. Mas não assim, ' $a$ ' nível de posto, eu acho que, 'a' nível central. Em relação aos exames, a alta complexidade, uma resolutividade mais rápida. Poderíamos ter garantia das referências, dos apoios matriciais [...]. A gente não tem essa garantia. Se houvesse, ajudaria muito. (PROF04; PROF13; PROF15; PROF23; PROF25; PROF27).

Um estudo realizado por Bezerra e Carvalho (2011), sobre os profissionais de saúde e os dispositivos de mediação da Atenção Básica, retrata que problemas estruturais podem dificultar as relações de troca. Os autores afirmam que, quando há falhas nas qualidades estruturais da unidade, ficam em risco a confiança e o respeito entre profissionais e usuários.

Compreender a interdependência do outro nas relações de trocas, significa reconhecer que não só os profissionais e a gestão são produtores do cuidado, e que os usuários, não são apenas os consumidores (LOPES, 2014). O 'respeito para com o outro', foi destacado, também, no DSC dos profissionais e usuários como fator importante nas relações do acolhimento. "Com certeza, posso contribuir, respeitando os profissionais. Eu acho que isso é essencial" (USU01).

O usuário pode contribuir, sim. Eu acho que ele deveria ter mais respeito pelo idoso, pelas pessoas que têm prioridade naquele momento. Há pessoas que não entendem que existem prioridades e, naquele momento, uma marcação de consulta não é prioridade, se tem uma criança com febre. Então, as pessoas precisam se organizar nessa questão de respeito ao próximo. Se, pelo menos, eles fossem mais coerentes, mais educados, mais conscientes [...] o posto não vai resolver tudo que eles querem. (PROF03; PROF06; PROF12; PROF18; PRPF24; PROF29).

Apesar de estar inserido, atualmente, em uma realidade que inibe o intercâmbio de dádivas e as trocas recíprocas com alta demanda, problemas estruturais, problemas internos enfrentados pela própria equipe e opinião da população frente ao modelo médico-centrado, o acolhimento tem se mostrado como a ferramenta de inovação institucional proposta pela $\mathrm{PNH}$, que tem qualificado as relações humanas e contribuído para a eficácia do serviço. O cotidiano das unidades não se resume a embates e desacordos. Iniciativas como o acolhimento, mesmo com todas as dificuldades, têm favorecido a relação entre trabalhador e usuário (BEZERRA; CARVALHO, 2011; LOPES, 2014).

A relação de reciprocidade com a presença de dádivas como afetividade, justiça, equidade, obrigação, respeito, gratidão e responsabilidade perante o outro, são promovidas pelas relações sociais vivenciadas no acolhimento entre profissionais e usuários. Porém, não é em todas as relações que as dádivas se configuram de maneira positiva: sentimentos como vingança, injustiça, desrespeito e ingratidão podem estar presentes nessas relações.

A forma como a reciprocidade se manifesta no acolhimento depende de critérios como: as características individuais, tanto dos profissionais como dos usuários; as condições em que estes profissionais estão inseridos para realizar o cuidado; a compreensão das formas como os usuários procuram cuidado, bem como eles propõem a resolução dos problemas de saúde (PINHEIRO; MARTINS, 2011).

Nesse sentido, construir e fortificar vínculos por meio das relações recíprocas exige do profissional um conhecimento prático ampliado, com ressignificação de práticas embasadas na lógica de cuidado integral, mesmo diante das dificuldades presentes na sua realidade (LOPES, 2014). 
Tais reflexões reavivam a proposta do cuidado como uma estratégia relevante para a consumação da integralidade, com adoção de uma sabedoria prática, permitindo a permeabilidade do racionalismo técnico para aspectos não técnicos, essenciais à eficácia do próprio cuidado (VILAR, 2014).

\section{Conclusões}

Em sua política de humanização, o Ministério da Saúde, se apropriou de diversas ferramentas para estabelecer redes, vínculos e a corresponsabilização entre usuários, trabalhadores e gestores. Entre essas ferramentas, o acolhimento surge como uma prática que possibilita reflexão e mudança nos modos de operar a assistência, pois questiona as questões clínicas e relacionais nos processos de trabalho em saúde e os modelos de atenção e gestão, bem como as relações entre trabalhadores e usuários no cotidiano dos serviços.

Pode-se afirmar que o acolhimento, pelo fato de possibilitar a humanização do atendimento, sugere a garantia de acesso a este, entendido como ingresso e apropriação do serviço de saúde oferecido. Refere-se à atenção dada aos problemas de saúde do usuário, de maneira qualificada, disponibilizando um feedback que proporcione a solução do seu problema ou o encaminhamento do mesmo para uma possível resolução. Por conseguinte, deverá promover a resolubilidade, já que o objetivo do trabalho em saúde é elucidar efetivamente o problema do usuário. $\mathrm{O}$ compromisso com o problema de saúde vai além da assistência propriamente dita, está relacionado também ao vínculo necessário entre o serviço e a comunidade que é usuária.

Os critérios que provocam influências na normatização do processo de trabalho do acolhimento também tiveram repercussões nas relações de reciprocidade entre trabalhadores e usuários, contribuindo para fortalecer ou enfraquecer os vínculos entre eles. De modo geral, no DSC dos profissionais e usuários, é evidente que as relações entre eles melhorou depois da implementação do acolhimento, favorecendo a troca de dádivas.

O DSC abordou os principais fatores que possibilitaram que dádivas como afetividade, respeito, justiça, responsabilidade e cuidado para com o próximo circulassem dentro das relações de reciprocidade, destacando-se o acesso (ao profissional e ao serviço), a resolutividade, a atitude acolhedora e a responsabilização para com os usuários.

Porém, há outros fatores no discurso que impedem as relações recíprocas entre trabalhadores e usuários, como estrutura física deficiente, demanda excessiva, precariedade da rede de referência, visão do usuário médico-centrada, vulnerabilidade da população e não entendimento do usuário sobre o acolhimento. Esses fatores permitiram a troca de dádivas egoístas como desafeto, descrença, desconfiança, desrespeito e injustiça.

Portanto, é importante discutir sobre o tipo de sentimento que cada caso produz no profissional: indiferença burocrática; desafio profissional; vontade de ajudar; e indisposição em função de alguma característica do usuário, como alcoolismo, dependência de drogas, violência, religião, ideologia etc. Do mesmo modo, o usuário oferece, aos profissionais e ao serviço de saúde, diferentes afetos que necessitam ser compreendidos pelos dois lados: dependência absoluta do técnico; esperança mágica; revolta; e desafio, entre outros. Esses sentimentos não devem impedir as relações recíprocas nem comprometer o vínculo de cuidado entre trabalhadores e usuários.

\section{Colaboradores}

Todos os autores/coautores contribuíram substancialmente para a concepção e o planejamento deste trabalho, bem como para a análise e a interpretação dos dados; para a elaboração do manuscrito e a revisão crítica do conteúdo. Todos igualmente participaram da aprovação da versão final do manuscrito. 


\section{Referências}

BEZERRA, R. S.; CARVALHO, E. L. Profissionais de saúde e dispositivos de mediação na atenção básica. In: PINHEIRO, R.; MARTINS, P. H. (Org.). Usuários, redes sociais, mediações e integralidade em saúde. Rio de Janeiro: CEPESC: IMS-UERJ; Recife: Editora Universitária UFPE; São Paulo: ABRASCO, 2011. p. 149-160.

BRASIL. Ministério da Saúde. Comissão Nacional de Ética em Pesquisa. Diretrizes e normas regulamentadoras para pesquisa envolvendo seres humanos: resolução CNS 466/12 e outras. 2012. Disponível em: <http:// conselho.saude.gov.br/resolucoes/2012/Reso466.pdf>. Acesso em: 13 nov. 2013.

Ministério da Saúde. Secretaria de Atenção à Saúde. Departamento de Atenção Básica. Acolhimento à demanda espontânea. Brasília, DF: Ministério da Saúde, 2011.

Ministério da Saúde. Secretaria de Atenção à Saúde. Núcleo Técnico da Política Nacional de Humanização. HumanizaSUS: Documento base para gestores e trabalhadores do SUS. 4. ed. Brasília, DF: Ministério da Saúde, 2010.

Ministério da Saúde. Secretaria Executiva. Núcleo Técnico da Política Nacional de Humanização. Humaniza SUS. Política Nacional de Humanização: a humanização como eixo norteador das práticas de atenção e gestão em todas as instâncias do SUS. 2004. Disponível em: <http://dtr2001.saude.gov.br/editora/ produtos/impressos/folheto/040923FL.pdf >. Acesso em: 13 nov. 2012.

CAMPOS, G. W. S. Clínica e saúde coletiva compartilhadas: teoria Paidéia e reformulação ampliada do trabalho em saúde. In: CAMPOS, G. W. S. et al. (Org.). Tratado de Saúde Coletiva. São Paulo: Hucitec; Rio de Janeiro: Fiocruz, 2006. p. 41-80.

CAVALCANTE FILHO, J. B. et al. Acolhimento coletivo: um desafio instituinte de novas formas de produzir o cuidado. Interface - Comunicação, Saúde, Educação, Botucatu, v. 13, n. 31, p. 315-328, 2009.

\section{LEFÈVRE, F.; LEFÈVRE, A. M. Discurso do Sujeito} Coletivo: um novo enfoque em pesquisa qualitativa (desdobramentos). Caxias do Sul, RS: EDUCS, 2003.

Depoimentos e discursos: uma proposta de análise em pesquisa social. Brasília: Liber Livro, 2005.
Pesquisa de representação social: um enfoque qualiquantitativo: a metodologia do discurso do sujeito coletivo. 2. ed. Brasília: Liber Livro, 2012.

LOPES, A. S. Acolhimento prescrito $x$ real: uma análise sobre as relações entre trabalhadores e usuários na Estratégia Saúde da Família. 2014. 120 f. Dissertação (Mestrado em Saúde da Família) - Centro de Ciências da Saúde, Universidade Federal do Rio Grande do Norte, Natal, 2014.

MAUSS, M. Ensaio sobre a dádiva: forma e razão da troca nas sociedades arcaicas. In: _ـ Sociologia e antropologia. São Paulo: Cosac Naify, 2003. p. 183-314.

MENDES, R. N. S. Humanização \& acolhimento: uma revisão sistemática de literatura sobre a assistência no Sistema Único de Saúde. 2010. 40 f. Monografia (Especialização em Gestão em Sistemas e Serviços de Saúde) - Centro de Pesquisa Aggeu Magalhães, Fundação Oswaldo Cruz, Recife, 2010.

MITRE, S. M.; ANDRADE, E. G.; COTTA, R. M. M. Avanços e desafios do acolhimento na operacionalização e qualificação do Sistema Único de Saúde na Atenção Primária: um resgate da produção bibliográfica do Brasil. Ciência \&t Saúde Coletiva, Rio de Janeiro, v. 17, n. 8, p. 2071-2085, 2012.

PINHEIRO, R.; MARTINS, P. H. (Org.). Usuários, redes sociais, mediações e integralidade em saúde. Rio de Janeiro: CEPESC / IMS-UERJ; Recife: UFPE; São Paulo: ABRASCO, 2011

SABOURIN, E. Marcel Mauss: da dádiva à questão da reciprocidade. Revista Brasileira de Ciências Sociais, São Paulo, v. 23, n. 66, p. 131-208, 2008.

SCHMIDT, M. B.; FIGUEIREDO, A. C. Acesso, acolhimento e acompanhamento: três desafios para o cotidiano da clínica em saúde mental. Rev. Latinoam. Psicopat. Fund., São Paulo, v. 12, n. 1, p. 130-140, 2009.

VILAR, R. L. A. Humanização na Estratégia Saúde da Família. São Caetano do Sul: Yendis, 2014.

Recebido para publicação em novembro de 2014

Versão final em fevereiro de 2015

Conflito de interesses: inexistente

Suporte financeiro: não houve 